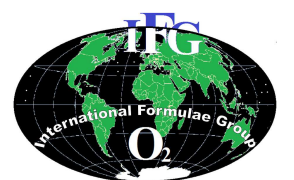

\title{
In vitro screening of NIPRD-AH1 on CYP3A4 activity for plausible herb-drug interaction
}

\author{
Bulus ADZU ${ }^{1 *}$, Kudirat Bola MUSTAPHA ${ }^{2}$, Roslyn THELINGWANI ${ }^{3}$, \\ Collen MASIMIREMBWA ${ }^{3}$ and Karniyus Shingu GAMANIEL ${ }^{4}$ \\ ${ }^{I}$ Department of Pharmacology and Toxicology, National Institute for Pharmaceutical Research and \\ Development (NIPRD), PMB 21, Abuja, Nigeria. \\ ${ }^{2}$ Department of Medicinal Chemistry and Quality Control (MC \& QC), NIPRD, PMB 21, Abuja, Nigeria. \\ ${ }^{3}$ African Institute of Biomedical Science and Technology (AiBST), Wilkins Hospital, Cnr Tongogara/Rekai \\ Tangwena, Harare, Zimbabwe. \\ ${ }^{4}$ Director General/Chief Executive Officer, NIPRD, PMB 21, Abuja, Nigeria. \\ *Corresponding author; Current address: Laboratório de Farmacologia, Departamento de Ciências Básicas \\ em Saúde, Faculdade de Medicina, Universidade Federal de Mato Grosso, Cuiabá - MT, Brazil. Tel: +55 (65) \\ 81461081; E-mail: bulusadzu@yahoo.com
}

\begin{abstract}
NIPRD-AH1 is being developed from freeze-dried aqueous extract of Andrographis paniculata at the National Institute for Pharmaceutical Research and Development (NIPRD), Abuja Nigeria as immunestimulant for HIV infected patients. The aim of this study was to evaluate the effect of NIPRD-AH1 on human cytochrome P450 3A4 (CYP3A4) drug metabolising enzyme in order to generate clinically significant data for its safe and efficacious use. Activity on CYP3A4 was measured with and without the addition of NIPRD-AH1 in a reaction medium with testosterone $(70 \mu \mathrm{M})$ as CYP3A4 substrate, and ketoconazole $(2.5 \mu \mathrm{M})$ as positive inhibitor. The metabolites formed after the enzymatic reactions were quantified by validated HPLC techniques. Results showed NIPRD-AH1 exhibiting low $\mathrm{IC}_{50}$ value of $0.03 \mathrm{mg} / \mathrm{ml}$, indicating that its metabolic processes are likely to inhibit CYP3A4. This suggests possibility of herb-drug interaction, with potential implication on concomitant administration of NIPRD-AH1 with CYP3A4 substrates. We therefore suggested that this effect be examined in vivo in order to draw a definitive conclusion.
\end{abstract}

(C) 2014 International Formulae Group. All rights reserved.

Keywords: Andrographis paniculata, NIPRD-AH1, CYP3A4, herb-drug interaction.

\section{INTRODUCTION}

Andrographis paniculata Nees [Acanthaceae] -- Pl. Asiat. Rar. (Wallich). iii. 116. (IK) (IPNI, 2012) is a bitter annual herb, native to tropical Asian countries, and is distributed in other regions of the world (Farnsworth and Soejarto, 1991). The plant is reputed for its medicinal value, necessitating a wide array of studies conducted on it by researchers. Results from these studies show that the plant exhibited various biological efficacies in both experimental and clinical studies, and also contained useful phytochemicals; detailed in the recent review 
by Okhuarobo et al. (2014). The plant is domesticated at the National Institute for Pharmaceutical Research and Development (NIPRD), Abuja Nigeria with a seed obtained from India in the 1990s. Its use was popular among HIV patients under the name Conavir before anti-HIV drugs became readily available (Ameh et al., 2010). The aqueous freeze-dried leaves extract of Andrographis paniculata (NIPRD-AH1) is being developed at NIPRD as immune-stimulant for Human Immune Virus (HIV) infected patients.

The use of herbal medicines either alone or with antiretroviral (ARVs) therapy is widespread among patients living with HIV (Duggan et al., 2001). This should be of concern especially with evidences of pharmacokinetic interactions between herbal products and ARVs (Lamorde et al., 2012). However, of recent, there has been growing awareness of herb-drug interaction as herbal remedies usage became popular. Pharmacology and toxicology research had been advocated on such herbal medications to ensure validity, safety and efficacy (Calapai and Caputi, 2007). Therefore, there is the need to make scientific evidences on these herbal products available for users and caregivers. Much attention is being given to herbal medicines interactions with cytochrome (CYP) 450 drug metabolizing enzymes. Of its many subtypes, one of the most important isoform is CYP3A4 (Nerbert and Russell, 2002), being involved in the metabolism of majority of clinically used drugs. For this reason, CYP3A4 is recognized as a major candidate for pharmacokinetic interactions (Schrøder-Aasen et al., 2012). Interestingly, most of the ARVs currently approved for use are metabolized in the liver by CYP3A4 (PAGAA, 2014). Previous studies with extracts of Andrographis paniculata on these enzymes shows that the extracts effectuate mouse hepatic cytochrome P450 enzymes (Jarukamjorn et al., 2006); and inhibited human hepatic CYP2C19 (Pan et al., 2011). The objective of this study is to assess potential or otherwise of clinical drug interaction by testing the effect of NIPRDAH1 on human hepatic CYP3A4 in order to generate useful data for guidance towards its safe and efficacious use (Adzu et al., 2013).

\section{MATERIALS AND METHODS \\ Herbal product (NIPRD-AH1) \\ NIPRD-AH1 preparations,}

standardisation, physicochemical and other quality control variables have been reported (Ameh et al., 2010). Briefly, aerial parts of Andrographis paniculata (voucher number NIPRD/H/3720) were harvested and subsequently air-dried under shade, grounded into powder, extracted with distilled water, filtered and freeze-dried. The freeze dried extract was evaluated to ensure its compliance with an already established standard and samples were delivered to the African Institute of Biomedical Science and Technology (AiBST), Harare, Zimbabwe in January 2010 for the enzyme assay. NIPRDAH's limit of solubility in aqueous solution was estimated by turbidimetric assay on plate reader with absorbance monitored at $595 \mathrm{~nm}$.

\section{CYP3A4 enzyme assay}

Effect of NIPRD-AH1 on CYP3A4

(Cypex Ltd, UK) activity was first investigated at 2 concentrations; low (0.02 $\mathrm{mg} / \mathrm{ml})$ and high $(2 \mathrm{mg} / \mathrm{ml})$. Inhibition of the CYP activity by more than $20 \%$ was considered significant. In this case, the $\mathrm{IC}_{50}$ value was determined using 8 concentrations range $(0.001-2 \mathrm{mg} / \mathrm{ml})$ of NIPRD-AH1 and the data analysed using nonlinear regression.

The incubation was performed at $37{ }^{\circ} \mathrm{C}$ in reactive mixtures with a final volume of $300 \mu \mathrm{L}$, consisting of: $5 \mu \mathrm{L}$ of $0.5 \mathrm{mg} / \mathrm{ml}$ CYP3A4, $20 \mu \mathrm{L}$ of $0.1 \mathrm{M} \mathrm{pH} 7.4 \mathrm{KPO}_{4}$ buffer, $20 \mu \mathrm{L}$ of $\mathrm{MgCl}_{2}, 5 \mu \mathrm{L}$ of $70 \mu \mathrm{M}$ testosterone (Sigma-Aldrich, St. Louis, MO), and $135 \mu \mathrm{L}$ of water, with and without the addition of 4 $\mu \mathrm{L}$ of NIPRD-AH1 or $2.5 \mu \mathrm{M}$ Ketoconazole (positive control). The incubation was started by $10 \mu \mathrm{L}$ of the marker substrate $(1 \mathrm{mM}$ NADPH) and stopped after 15 min with 100 $\mu \mathrm{L}$ of ice cold methanol (Adzu et al., 2014). 
The mixture was centrifuged (at 10,000 g) for 10 min at $4{ }^{\circ} \mathrm{C}$, and the supernatant transfer to High Performance Liquid Chromatography (HPLC) vials for analysis. All working solutions were freshly prepared before each experiment.

\section{HPLC analysis}

The analytical procedure was performed using validated HPLC methodology with Agilent HPLC system coupled with a UV detector under the following conditions: mobile phase, solvent A: $60 \%$ methanol; solvent B: $40 \% 50 \mathrm{mM}$ $\mathrm{KH}_{2} \mathrm{PO} 4$; flow rate of $1 \mathrm{ml} / \mathrm{min}$; injection volume of $100 \mu \mathrm{L}$; analytical column: C18, $4.6 \times 150 \mathrm{~mm}, 5 \mu \mathrm{M}$; detection wavelength of $254 \mathrm{~nm}$ and run time of $19 \mathrm{~min}$ at room temperature (Adzu et al., 2014).

\section{RESULTS AND DISCUSSION}

In vitro assays such as this are the most practical means of screening for potential interaction for herbal products. The solubility test shows that NIPRD-AH1 has solubility above $2 \mathrm{mg} / \mathrm{ml}$ in water, indicating that it was soluble at that concentration being the highest concentration that was used in the inhibition assay. The enzyme assay showed that NIPRD-AH1 inhibited CYP3A4 activity by more than $50 \%$, with $\mathrm{IC}_{50}$ value of 0.03 $\mathrm{mg} / \mathrm{ml}$. The $\mathrm{IC}_{50}$ profile is presented in Figure 1.

If CYP activity is altered-so too is the bioavailability of drugs that are metabolised by it. The way herbal products alter the action of CYP3A4 is by inhibition, causing toxicity in most cases (Lau et al., 2013). However, many phytodrugs have similar activity, warranting further studies in vivo to determine whether the interactions are of significant issue. This is because such in vitro observation might not necessarily result in major interaction in vivo. There is the possibility of other effects; for example, solubility and permeability parameters and other extraction and manufacturing process (Lipinski et al., 1997).

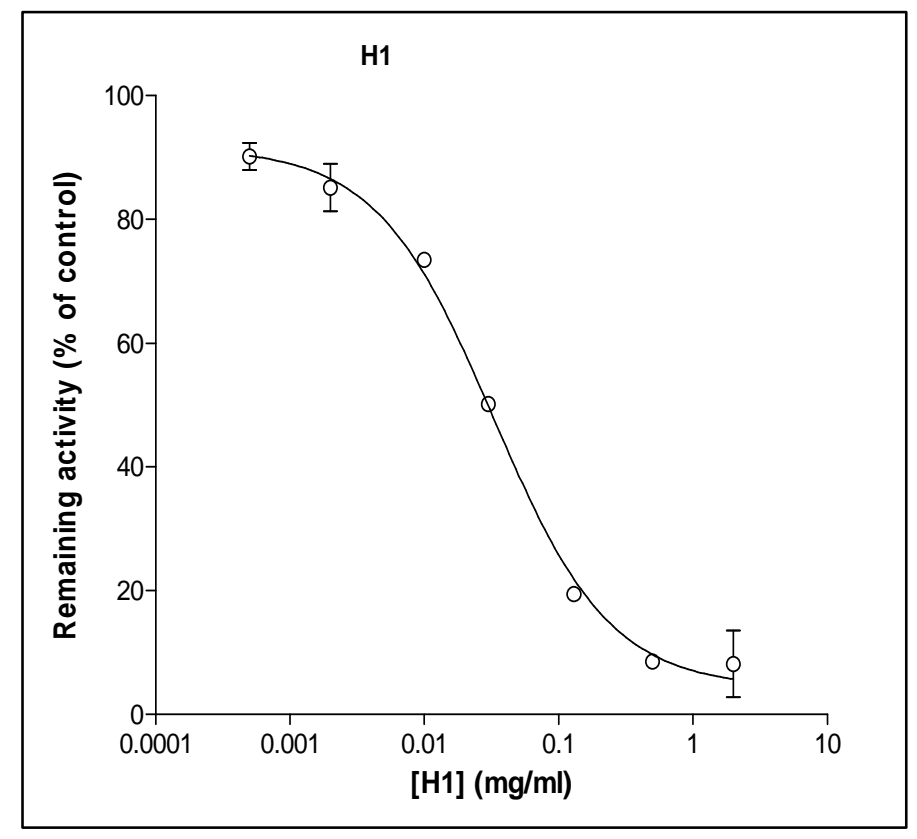

Figure 1: Effect of NIPRD-AH1 on CYP3A4 activity. 


\section{Conclusion}

This in vitro result shows that NIPRDAH1 is a potential inhibitor of CYY3A4. Therefore, its clinical relevance needs to be assessed in vivo to put it in proper prospective (FDA, 2012). Equally, the fact that inhibition of CYP3A4 has been exploited in some cases for its potential clinical benefits (Lee et al., 2007) can also be explored.

\section{ACKNOWLEDGEMENTS}

There is no conflict of interest with the authors. NIPRD-AH1 was prepared at NIPRD, while the enzyme assay was performed at AiBST through a Memorandum of Understanding (MoU) with NIPRD (NIPRD/CWA/ADM-473). The authors are grateful to the Department of Medicinal Plant Research and Traditional Medicine, NIPRD for the preparing the sample, Department of MC \& QC for standardising the product, and Kimberley Smasher of AiBST for technical assistance. The authors also appreciate Instituto Nacional de Ciência e Tecnologia em Áreas Úmidas (INAU) and Conselho Nacional de Desenvolvimento Científico e Tecnológico (CNPq), Brazil for research visit fellowship (151135/2014-2) to B. Adzu.

\section{REFERENCES}

Adzu B, Mustapha KB, Masimirembwa C, Obodozie O, Kirim RA, Gamaniel KS. 2013. Simulation of metabolism-based herb-drug interaction: towards safe and efficacious use of NIPRD-AM1. Avicenna J. Phytomed., 3(3): 201 - 204.

Adzu B, Masimirembwa C, Mustapha KB, Thelingwani R, Kirim RA. Gamaniel KS. 2014. Effect of NIPRISAN ${ }^{\circledR}$ on CYP3A4 activity in vitro. Eur. J. Drug Metab. Pharmacok. (In Press) doi: 10.1007/s13318-014-0173-1.

Ameh SJ, Obodozie OO, Inyang US, Abubakar MS, Garba M. 2010. Quality Control Tests on Andrographis paniculata Nees (Family: Acanthaceae) an Indian 'Wonder' plant Grown in
Nigeria. Trop. J. Pharm. Res., 9(4): 387 394.

Calapai G, Caputi AP. 2007. Herbal medicines: can we do without pharmacologist. Evid. Based Complement. Alternat. Med., 4: 41-43.

Duggan J, William S, Peterson BS, Schutz M, Khuder S, Charkraborty, J. 2001. Use of complementary and alternative therapies in HIV-infected patients. AIDS Patient Care and STDs 15(3): 159 - 167.

Farnsworth NR, Soejarto DD. 1991. Global Importance of Medicinal Plants. In The Conservation of Medicinal Plants, Akerelev O, Heywood V, Synge H (eds). Cambridge University Press: Cambridge; 25-51.

IPNI. 2012. The International Plant Names Index 2012. [http://www.ipni.org], accessed on: 13 May, 2014.

Jarukamjorn K, Don-in K, C. Makejaruskul C, Laha T, Daodee S, Pearaksa P, Sripanidkulchai B. 2006. Impact of Andrographis paniculata crude extract on mouse hepatic cytochrome P450 enzymes. J. Ethnopharmacol., 105(3): 464-467.

FDA. 2012. Guidance for Industry Drug Interaction Studies - Study Design, Data Analysis, Implications for Dosing, and Labeling Recommendations. DRAFT GUIDANCE. (http://www.fda.gov/ downloads/Drugs/GuidanceComplianceR egulatoryInformation/Guidances/UCM29 2362.pdf).

Lamorde M, Byakika-Kibwika P, Merry C. 2012. Pharmacokinetic interactions between antiretroviral drugs and herbal medicines. Brit. J. Hosp. Med., 73(3): 132-136.

Lau C, Mooiman KD, Maas-Baker RF, Beijnen JH, Schellens JHM, Meijerman I. 2013. Effect of Chinese herbs on CYP3A4 activity and expression in vitro. J. Ethnopharmacol., 149(2): 543-549.

Lee SS, Zhang B, He ML, Chang VSC, Kung HF. 2007. Screening of Active Ingredients of Herbal Medicine for 
Interaction with CYP450 3A4. Phytother. Res., 21(11): 1096-1099.

Lipinski CA, Lambardo F, Dominy B, Feeney PJ. 1997. Experimental and computational approaches to estimate solubility and permeability in drug discovery and development settings. $A d v$. Drug Deliv. Rev., 23(1): 3-25.

Nerbert DW, Russell DW. 2002. Clinical importance of the cytochromes $\mathrm{p} 450$. The Lancet, 360(9340): 1155 - 1162.

Okhuarobo A, Falodun JE, Erharuyi O, Imieje V, Falodun A, Langer P. 2014. Harnessing the medicinal properties of Andrographis paniculata for diseases and beyond: a review of its phytochemistry and pharmacology. Asian Pacific J. Trop. Dis., 4(3): 213 - 222.

Pan Y, Abd-Rashid BA, Z. Ismail Z, Ismail R, Mak JW, Pook PCK, Er HM, Ong CE.
2011. In vitro modulatory effects of Andrographis paniculata, Centella asiatica and Orthosiphon stamineus on cytochrome P450 2C19 (CYP2C19). J. Ethnopharmacol., 133(2): 881-887.

PAGAA (Panel on Antiretroviral Guidelines for Adults and Adolescents). 2014. Guidelines for the use of antiretroviral agents in HIV-1-infected adults and adolescents. Department of Health and Human Services. Available at http://aidsinfo.nih.gov/guidelines. Section accessed [June 3, 2014; p. 212 - 214].

Schrøder-Aasen T, Molden G, Nilsen OG. 2012. In vitro Inhibition of CYP3A4 by the Multiherbal Commercial Product Sambucus Force and its Main Constituents Echinacea purpurea and Sambucus nigra. Phytother. Res., 26(11): 1606-1613. 